\title{
Plasma rico em plaquetas combinado a hidroxiapatita na formação do calo ósseo em fraturas induzidas experimentalmente no rádio de cães
}

\author{
Platelet-rich plasma combined with hydroxyapatite on bone callus formation in experimental \\ radii fractures in dogs
}

\author{
Silmara Bonomi da Silva ${ }^{\mathrm{I}}$ Cássio Ricardo Auada Ferrigno ${ }^{\mathrm{II}}$ Franklin de Almeida Sterman ${ }^{\mathrm{II}}$ \\ Daniel Castelo Branco Baccarin ${ }^{\mathrm{I}}$ Karina Veloso Braga Yazbek ${ }^{\mathrm{III}}$ Caterina Muramoto \\ Marcos Amaku ${ }^{\text {IV }}$
}

\section{RESUMO}

Avaliou-se, no presente estudo, os efeitos do plasma rico em plaquetas (PRP) autógeno combinado a hidroxiapatita não-absorvível na formação do calo ósseo em fraturas diafisárias induzidas experimentalmente em rádio de cães $e$ fixadas com placas e parafusos ósseos. Foram utilizados oito cães adultos sem raça definida, machos ou fêmeas, com pesos compreendidos entre 5 e 15kg. Induziu-se na diáfise de ambos os rádios defeito ósseo correspondente a 25\% do diâmetro do mesmo. No rádio direito (grupo HA/PRP), implantou-se plasma rico em plaquetas combinado a hidroxiapatita. No rádio esquerdo (grupo HA), implantou-se somente a hidroxiapatita. Para a obtenção do PRP, empregou-se protocolo simplificado utilizando centrífuga laboratorial comum. Comparou-se entre os grupos a evolução clínica dos animais, o tempo de formação e a densidade do calo ósseo por exames radiográficos simples e pela técnica de densitometria óptica aos 15, 30, 45 e 60 dias de pós-operatório. Tanto na avaliação radiográfica como densitométrica não se observou diferença estatisticamente significante na evolução do calo ósseo entre os grupos $(P>0,05)$. No presente estudo, o PRP autógeno combinado à hidroxiapatita não-absorvível não acelerou o processo de formação do calo ósseo, comparado à hidroxiapatita somente.

Palavras-chave: plasma rico em plaquetas, hidroxiapatita, cães, calo ósseo, densitometria óptica.

\section{ABSTRACT}

The present study was aimed at evaluating the effects of autologous platelet-rich plasma (PRP) in combination with unabsorbable hydroxyapatite on bone callus formation in an experimental canine diaphyseal radius fracture stabilized with bone plate. Eight mature, male and female mongrel dogs were selected weighed 5 to $15 \mathrm{~kg}$. Bone defects were created, bilateral, in both radii diaphysis, corresponding to $25 \%$ of bone diameter. On the right radius (group HA/PRP), the defect was filled with PRP and hydroxyapatite. On the left radius (group HA), was placed hydroxyapatite alone. PRP was obtain by a simplified technique using a laboratory centrifuge. Clinical evaluations, bone formation and bone density by use of radiographic and optical densitometry, were compared between group HA/PRP and group HA after 15, 30, 45 and 60 days post surgery. The radiographic and densitometric study did not indicate a significant difference in the bone callus formation between the groups $(P>0.05)$. In the present study the autologous PRP in combination with unabsorbable hydroxyapatite could not accelerated the bone callus in comparison with hydroxyapatite alone.

Key words: platelet-rich plasma, hydroxyapatite, dogs, bone callus, optic densitometry.

\section{INTRODUÇÃO}

A regeneração óssea depende de fatores biomecânicos e biológicos. A atuação dos fatores de crescimento locais e sistêmicos nas diferentes fases da regeneração (inflamação, reparo e remodelação) são essenciais para o recrutamento de células imediatamente após a injúria, assim como para potencializar a produção

IPrograma de Pós-graduação em Medicina Veterinária, Departamento de Cirurgia, Faculdade de Medicina Veterinária e Zootecnia, Universidade de São Paulo (FMVZ/USP). Av. Prof. Dr. Orlando Marques de Paiva, 87, 05508-900, São Paulo, SP, Brasil. Email:bonomis@usp.br. Autor para correspondência.

IIDepartamento de Cirurgia, FMVZ-USP, São Paulo, SP, Brasil.

IIIDepartamento de Cirurgia e Anestesiologia, Universidade Cruzeiro do Sul (UNICSUL), São Paulo, SP, Brasil, Universidade do Grande ABC (UNIABC), São Caetano do Sul, SP, Brasil.

${ }^{\text {IV } D e p a r t a m e n t o ~ d e ~ M e d i c i n a ~ V e t e r i n a ́ r i a ~ P r e v e n t i v a ~ e ~ S a u ́ d e ~ A n i m a l, ~ F M V Z / U S P, ~ S a ̃ o ~ P a u l o, ~ S P, ~ B r a s i l . ~}$ 
de tecido ósseo (REMEDIOS, 1999). Por estarem no sangue, as plaquetas são as primeiras células presentes na lesão, atuam no processo de hemostasia e liberam fatores de crescimento responsáveis pela migração e ativação das células que iniciarão o processo de reparo de tecidos moles e ósseos (CARLSON, 2000).

O plasma rico em plaquetas (PRP) é fonte natural de fatores de crescimento, sendo obtido a partir da centrifugação do sangue total. Por ser autógeno, impede a transmissão de doenças infecto-contagiosas e reações imunológicas (OBARRIO et al., 2000). O PRP aumenta principalmente a concentração de fatores de crescimento derivado das plaquetas (FCDP) e fator de transformação de crescimento-ß (FTC-ß), demonstrado através de estudos de anticorpos monoclonais, que também indicaram a presença de receptores para estes fatores nas células osteoprogenitoras e nas célulastronco da medula óssea (MARX et al., 1998).

Segundo MARX et al. (1998), para ser eficaz, o PRP deve apresentar concentração plaquetária (incremento plaquetário) 338\% superior ao número de plaquetas presentes no sangue total. WHITMAN et al. (1997) e OBARRIO et al. (2000) consideram como ideal 500.000 a 1.000 .000 de plaquetas microlitro-1.

O PRP pode ser obtido através de diferentes protocolos e necessita centrífuga laboratorial comum, separador específico para obtenção do PRP, ou aparelhos sofisticados como centrífuga com sistema de separação de células e autotransfusão (ANITUA, 1999; OBARRIO et al., 2000; KIM, 2002a,b; WEIBRICH et al., 2002; WILTFANG et al., 2004). Todos os procedimentos devem ser realizados com técnica asséptica e simultaneamente ao preparo do leito receptor. A quantidade de sangue necessária é variável e depende do método de obtenção utilizado (MARX et al., 1998).

O plasma rico em plaquetas possui propriedades osteoindutoras e tem sido utilizado desde a década de 90 como fonte autógena de fatores de crescimento combinado aos diferentes enxertos e substitutos ósseos no intuito de estimular a regeneração óssea, aumentando a velocidade de formação óssea e sua qualidade. É geralmente utilizado no homem para reconstruções ósseas maxilofaciais, levantamento de seios maxilares, defeitos ósseos alveolares, bolsas periodontais e em implantodontia, com a finalidade de melhorar a osteointegração dos implantes dentários (MARX et al., 1998; ANITUA, 1999; OBARRIO et al., 2000; FENNIS et al., 2002; WILTFANG et al., 2003; FENNIS et al., 2004; MAZOR et al., 2004; GERARD et al., 2006; SIMON et al., 2006). Porém, a literatura referente ao uso do plasma rico em plaquetas em ossos longos tanto no homem como nos animais é escassa (FLORYAN \& BERGHOFF, 2004; HAUSCHILD et al., 2005; DALLARI et al., 2006; SARKARA et al., 2006).

Em animais, a aplicação experimental do PRP em procedimentos maxilofaciais e peri-implantes dentários apresentam resultados controversos (AGHALOO et al., 2002; GRAGEDA et al., 2005; ROLDÁN et al., 2004; SÁNCHEZ et al., 2005), sugerindo a possibilidade do processo de regeneração óssea no modelo animal diferir do processo no homem (JASKE et al., 2003).

A hidroxiapatita é material cerâmico com característica estrutural semelhante à fase mineral do tecido ósseo e sua porosidade influencia na osteocondutividade (BLOKHUIS et al., 2000). Estudo experimental em cães demonstra a osteointegração do implante sem apresentar efeitos adversos, confirmando a propriedade osteocondutora e a biocompatibilidade do substituto ósseo (CONG et al., 2001).

A densitometria óptica radiográfica é uma técnica radiológica não invasiva, precisa, de fácil execução e de baixo custo que avalia a variação da densidade mineral óssea por meio de imagens radiográficas (LOUZADA et al., 1998). A densitometria óptica radiográfica é indicada por LOUZADA et al. (1998) para transpor as limitações visuais e a subjetividade da interpretação radiográfica simples.

Investigaram-se os efeitos do PRP autógeno para fins cirúrgicos como adjuvante nas osteossínteses das fraturas com placas e parafusos ósseos, visando à aceleração do processo de formação do calo ósseo em rádio de cães.

\section{MATERIAL E MÉTODOS}

Foram utilizados oito cães adultos, sem raça definida, sete machos e uma fêmea, com idade aproximada de três anos, pesos compreendidos entre 5 e $15 \mathrm{~kg}$ e provenientes do Centro de Controle de Zoonoses de Mauá. Os animais foram previamente vacinados (óctupla e anti-rábica) e vermifugados. Para o controle de ectoparasitas, utilizou-se fipronil tópico. Realizou-se hemograma completo e contagem de plaquetas no período pré-operatório e nova contagem de plaquetas no período pré-operatório imediato. Foram selecionados para o estudo os animais sadios que não apresentaram alterações no exame clínico e nos exames laboratoriais.

Os cães foram submetidos a jejum hídrico de seis horas e alimentar de 12 horas. Como medicação pré-anestésica, administraram-se acepromazina e morfina por via intramuscular. Para a indução anestésica, administrou-se propofol intravenoso e a manutenção anestésica foi realizada com isofluorano.

Ciência Rural, v.37, n.4, jul-ago, 2007. 
Realizou-se intervenção cirúrgica nos rádios bilateralmente e considerou-se o rádio direito como grupo HA/PRP e o rádio esquerdo como grupo HA. Após o preparo rotineiro dos campos operatórios, realizou-se abordagem das diáfises dos rádios segundo PIERMATTEI \& FLO (1999). Após a visibilização da diáfise do osso, iniciaram-se os procedimentos de ostectomia. A ulna permaneceu íntegra. Para melhor estudo e quantificação da formação do calo ósseo, retirou-se, com auxílio de serra oscilatória pneumática, fragmento ósseo e periósteo com aproximadamente $25 \%$ do diâmetro do rádio. Implantou-se no foco de fratura do grupo HA somente hidroxiapatita sinterizada ${ }^{a}$ e, no grupo HA/PRP, hidroxiapatita sinterizada combinada ao PRP. A quantidade de hidroxiapatita implantada, em ambos os grupos, foi o suficiente para preencher o foco de fratura.

Findada esta etapa operatória, iniciou-se a técnica de colocação de placa óssea com seis furos e seis parafusos, tamanho 2.7, segundo PIERMATTEI \& FLO (1999). Realizou-se a sutura da musculatura e do tecido subcutâneo com fio de poliglactina 3-0 em pontos simples, contínuos e, posteriormente, a sutura de pele com nailon 3-0 em pontos simples separados.

Nos animais previamente anestesiados, após tricotomia e anti-sepsia, realizou-se a colheita de sangue venoso da jugular em quatro tubos estéreis de $3 \mathrm{ml}$ contendo anticoagulante citrato de sódio . Os tubos foram centrifugados a 1.000rpm, equivalente a 90 gravidades (g) por 10 minutos, em centrífuga laboratorial comum $^{\text {b }}$, de acordo com o protocolo de KIM et al. (2002a; 2002b). Após a primeira centrifugação, pipetou-se todo o plasma e a camada leucoplaquetária, os quais foram transferidos para dois frascos secos estéreis e realizou-se a segunda centrifugação, a 1.500rpm por 10 minutos (200g). Após a segunda centrifugação, foram descartados 2/3 do plasma sobrenadante com o auxílio de uma pipeta estéril e homogenizou-se cuidadosamente o plasma restante (1/3) às plaquetas, obtendo-se o plasma rico em plaquetas. Uma amostra do PRP foi separada para a contagem manual do número de plaquetas presentes. No momento da aplicação do enxerto ao leito receptor, adicionaram-se ao PRP e à hidroxiapatita $20 \%$ de tromboplastina cálcica ${ }^{\mathrm{c}}$ para a coagulação do PRP (FONTANA et al., 2004).

Findadas as etapas operatórias, foram confeccionados pensos no modelo de Robert Jones, que se mantiveram por sete dias. A analgesia no período pós-operatório imediato foi realizada com cetoprofeno por via intramuscular ( $2 \mathrm{mg} \mathrm{kg}^{-1}$ ), dipirona sódica (25mg $\mathrm{kg}^{-1}$ ) pela via intravenosa e doses adicionais de morfina $\left(0,2 \mathrm{mg} \mathrm{kg}^{-1}\right)$ pela via IV como medicação resgate, quando necessário. Os animais foram medicados no período pós-operatório com azitromicina (10 $\left.\mathrm{mg} \mathrm{kg}^{-1}\right)$ por via oral a cada 24 horas, durante sete dias; tramadol (3mg $\mathrm{kg}^{-1}$ ) a cada 12 horas, via oral (VO), durante cinco dias; dipirona sódica (25mg kg-1), VO, a cada 12 horas, durante cinco dias; e meloxican $\left(0,1 \mathrm{mg} \mathrm{kg}^{-1}\right)$, VO, a cada 24 horas, durante sete dias.

Os animais foram mantidos em gaiolas individuais durante três meses, alimentados com ração seca para cães adultos e água ad libitum. Após este período, os animais foram encaminhados para o programa de doação.

Avaliou-se diariamente a estabilidade dos focos de fratura através da palpação do membro, aumento de volume e dor na região da intervenção cirúrgica e a utilização do membro na deambulação. Os animais foram submetidos a exames radiográficos em projeção médio lateral, com técnica padronizada individualmente e semelhante em todos os momentos de observação, no momento pré-operatório (PRE) para o controle e nos momentos de observação pósoperatório imediato (POI), 15 dias (15D), 30 dias (30D), 45 dias (45D) e 60 dias (60D) de pós-operatório para avaliação da evolução do calo ósseo. Considerou-se a presença ou ausência de linha de fratura respeitando a seguinte graduação: $(0)=$ linha de fratura ausente; $(1)=$ linha de fratura pouco evidente; (2)= linha de fratura evidente e (3)= linha de fratura muito evidente.

Acompanhou-se também a presença ou ausência da reabsorção parcial dos grânulos de hidroxiapatita no foco de fratura. Os laudos foram realizados por médico veterinário radiologista "cego" para os diferentes tratamentos empregados.

Para a avaliação por meio da densitometria óptica radiográfica, fixou-se o penetrômetro de alumínio junto ao chassi, paralelamente ao eixo maior do osso radiografado. A escala de referência é constituída de 25 degraus, tendo o primeiro a espessura de $1 \mathrm{~mm}$, variando a seguir de $1 \mathrm{em} 1 \mathrm{~mm}$ até o vigésimo quinto. As imagens digitalizadas do rádio e do penetrômetro foram analisadas por meio do software de processamento e análise de imagem ImageLab ${ }^{\mathrm{d}}$.

Na análise estatística dos resultados entre diferentes momentos de observação de um mesmo grupo, empregou-se o teste de Friedman (ANOVA para medidas repetidas não-paramétricas) para a avaliação da linha de fratura, e o teste exato de Fisher para a avaliação da reabsorção parcial da hidroxiapatita. Para o confronto dos resultados entre os diferentes grupos no mesmo momento de observação, empregou-se o teste de Wilcoxon para a avaliação da linha de fratura, teste de McNemar para a avaliação da reabsorção parcial da hidroxiapatita e o teste-T para duas amostras (variâncias iguais) para a avaliação das densidades

Ciência Rural, v.37, n.4, jul-ago, 2007. 
minerais ósseas (DMO). Na análise de correlação do incremento plaquetário e para a avaliação radiográfica simples nos diferentes momentos de observação do grupo HA/PRP, empregou-se o teste de correlação de Spearman. O grau de significância estabelecido foi de $5 \%(\mathrm{P}<0,05)$.

\section{RESULTADOS}

As concentrações plaquetárias por $\mathrm{mm}^{3} \mathrm{e}$ incrementos plaquetários do PRP (\%) foram: cão $1=730.500 / 252,89$, cão $2=275.000 /-22,30$, cão3 $=652.500 / 51,40, \quad$ cão $4=465.000 / 100,43$, cão5 $=775.000 / 283,66$, cão6 $=800.000 / 125,99$, cão7=950.000/226,46 e cão8=1.145.000/385,17.

Todos os animais apresentaram apoio dos membros operados em todo o período pós-operatório, eixo ósseo mantido em todos os membros avaliados e boa evolução clínica, exceto um animal que desenvolveu sinais clínicos e radiográficos de osteomielite no rádio direito (grupo HA/PRP) no momento 30D, com ausência de falência do implante e sem apresentar claudicação. Houve a remissão dos sinais de osteomielite (lise óssea e drenagem de secreção) somente após a retirada do implante e do fragmento ósseo (sequestro).

A evolução do calo ósseo ocorreu de maneira favorável nos diferentes momentos em todos os animais e em ambos os membros. No grupo HA/ PRP, a evolução do calo ósseo apresentou diferença significante no confronto estatístico entre os momentos 15D e 60D, e, no grupo HA, entre os momentos POI e $60 \mathrm{D}$, e $15 \mathrm{D}$ e $60 \mathrm{D}(\mathrm{P}<0,05)$. Os resultados da probabilidade obtidos na comparação entre os grupos no mesmo momento de observação não foram estatisticamente significantes $(\mathrm{P}>0,05)$.

No momento 30D do grupo HA/PRP, houve correlação entre o incremento plaquetário e a evolução radiográfica do calo ósseo $(\mathrm{P}=0,0107)$ realizada pelo teste de correlação de Spearman, demonstrando que os animais que possuíam altas concentrações de plaquetas no PRP apresentaram linhas de fratura mais evidentes no momento 30D. Nos demais momentos, não houve correlação $(\mathrm{P}>0,05)$

Visibilizou-se no momento POI inúmeros pontos radiopacos correspondentes aos grânulos de hidroxiapatita implantados. No momento 15D, a diminuição da quantidade dos pontos radiopacos foi evidente e estatisticamente significante $(\mathrm{P}<0,05)$ tanto no grupo HA/PRP quanto no grupo HA. A reabsorção parcial da hidroxiapatita no grupo HA/PRP e no grupo HA nos mesmos momentos pós-operatórios foram confrontadas estatisticamente, não havendo diferenças significantes $(\mathrm{P}>0,05)$.

Em ambos os grupos, obteve-se a DMO média nos momentos POI, 15D, 30D, 45D e 60D maiores que a média do momento PRE; entretanto, não houve diferença significativa no confronto estatístico entre os dois grupos em cada momento. As médias das DMO (mmAl) em ambos os grupos estão apresentadas na tabela 1.

\section{DISCUSSÃO}

No presente estudo, o PRP combinado à hidroxiapatita não aumentou a velocidade de formação do calo ósseo por meio das avaliações radiográficas simples e densitométricas, estando de acordo com diversos estudos realizados em animais, os quais associaram o PRP a enxertos autólogos (AGHALOO et al., 2002; JASKE et al., 2003) e xenógenos (ROLDÁN et al., 2004; GRAGEDA et al., 2005; SÁNCHEZ et al., 2005).

A análise radiográfica simples do presente estudo demonstrou, em ambos os grupos, formação progressiva do calo ósseo, sem diferenças estatísticas entre eles, no mesmo momento de observação. Estes resultados radiográficos são semelhantes aos do estudo de AGHALOO et al. (2002) e SARKARA et al. (2006), que avaliaram os efeito do PRP em modelo animal. O animal que desenvolveu sinais de osteomielite não foi descartado do experimento por apresentar evolução favorável do calo ósseo em todos os momentos de observação.

Na avaliação radiográfica simples, a reabsorção parcial da hidroxiapatita foi mais evidente e estatisticamente significante no período 15D em ambos os grupos, demonstrando que a adição do plasma rico em plaquetas ao substituto ósseo implantado não alterou sua reabsorção, assim como observado por WILTFANG et al. (2003; 2004).

Devido à implantação da hidroxiapatita, radiopaca, no foco de fratura, observou-se aumento das densidades minerais ósseas (DMO) nos animais de ambos os grupos, nos momentos pós-operatórios. A hidroxiapatita não apresentou efeitos adversos, demonstrando sua biocompatibilidade conforme observado por CONG et al. (2001) em cães.

Mesmo sem diferença estatística na comparação dos resultados radiográficos e densitométricos entre os grupos, observou-se maior média da DMO no momento 45D no grupo HA/PRP (Tabela 1). Resultados semelhantes foram descritos por FENNIS et al. (2002; 2004), os quais sugeriram que o aumento discreto da densidade óssea foi devido ao 
Tabela 1 - Valores da densidade mineral óssea (DMO), média em milímetros de alumínio ( $\mathrm{mm} A \mathrm{l})$ e desvio padrão (DP) do grupo tratado com hidroxiapatita e plasma rico em plaquetas (HA/PRP) e grupo tratado com hidroxiapatita (HA) nos diferentes momentos de observação (PRE, POI, 15D, 30D, 45D e 60D).

\begin{tabular}{lcc}
\hline Momento & $\begin{array}{c}\text { Grupo HA/PRP } \\
\text { Média } \pm \text { DP }\end{array}$ & $\begin{array}{c}\text { Grupo HA } \\
\text { Média } \pm \text { DP }\end{array}$ \\
\hline PRE & $3,47 \pm 0,20$ & $3,46 \pm 0,16$ \\
POI & $5,10 \pm 0,47$ & $4,29 \pm 0,47$ \\
15D & $4,33 \pm 0,48$ & $4,42 \pm 0,46$ \\
30D & $4,53 \pm 0,46$ & $4,51 \pm 0,50$ \\
45D & $5,13 \pm 0,61$ & $4,74 \pm 0,52$ \\
60D & $4,96 \pm 0,40$ & $4,92 \pm 0,53$ \\
\hline
\end{tabular}

(PRE) pré-operatório. (POI) pós-operatório imediato. (15D) 15 dias de pós-operatório. (30D) 30 dias de pós-operatório. (45D) 45 dias de pós-operatório e (60D) 60 dias de pós-operatório.

consequente aumento na mineralização óssea estimulada pelo PRP.

A análise da densidade do defeito ósseo com PRP pode não demonstrar os efeitos estimulatórios da regeneração óssea, pois o PRP apresenta os fatores de crescimento FCDP, FTC-ß e FCI-I não-específicos, que atuam nos pré-osteoblastos, fibroblastos, nas células-tronco da medula e células mesenquimais indiferenciadas (MARX et al., 1998), estimulando o processo de regeneração óssea principalmente na fase inicial (CARLSON, 2000). Por ser pouco mineralizado, a avaliação radiográfica do osso jovem pode não apresentar sensibilidade e, neste caso, a avaliação invasiva histomorfométrica é considerada o método conclusivo, conforme GERARD et al. (2006).

O protocolo de obtenção do PRP utilizado obedeceu às técnicas assépticas, porém apresenta como desvantagem a possibilidade de contaminação durante a transferência do plasma para o segundo frasco antes da segunda centrifugação e durante a retirada do plasma sobrenadante (pobre em plaquetas) após a segunda centrifugação. Os sinais de osteomielite evidenciados em um cão podem estar associados à contaminação do campo operátorio durante a intervenção cirúrgica ou à contaminação do plasma rico em plaquetas, sendo que o único membro que apresentou esses sinais foi tratado com o PRP.

No presente estudo, foi adotado o protocolo simplificado para a obtenção de plasma rico em plaquetas realizado por KIM et al. (2002a; 2002b) em cães, o qual necessita de centrífuga laboratorial comum, pequeno volume sangüíneo e baixo custo financeiro, o que torna o protocolo viável na Medicina Veterinária.
A descrição de técnicas simplificadas de obtenção do PRP e que dispensam a utilização de equipamentos sofisticados podem ser encontradas atualmente (ANITUA, 1999; KIM et al., 2002a; 2002b). O gel plaquetário facilitou a manipulação dos grânulos de hidroxiapatita, sua implantação e permanência no leito receptor, assim como observado por SIMON et al. (2006).

Não foi possível no estudo o incremento plaquetário superior a 338\%, como proposto por Marx et al. (1998) e obtido por KIM et al. (2002a; 2002b). Em seis animais (75\%), obteve-se número de plaquetas no PRP superior a $500.000 \mathrm{~mm}^{-3}$, considerado por OBARRIO et al. (2000) e WHITMAN et al. (1997) número ideal. O incremento plaquetário variou entre 51,4 a 385,17\% e, em um caso (12,5\%), obteve-se decréscimo no número de plaquetas do PRP comparado ao sangue total. O decréscimo no número plaquetário foi relatado por GRAGEDA et al. (2005) no PRP de ovelhas e por WEIBRICH et al. (2002) em PRP humanos, obtidos em separadores específicos para PRP. A possibilidade de agregação plaquetária justificaria a quantificação reduzida no PRP, já que as plaquetas agregadas podem não ser contadas (GRAGEDA et al., 2005).

WILTFANG et al. (2004) observaram o aumento na quantidade de osso neoformado diretamente relacionado ao aumento da concentração de plaquetas. No presente estudo, observou-se correlação entre o incremento plaquetário do PRP e a evolução do calo ósseo somente no momento 30D no grupo HA/PRP. Entretanto, a comparação da evolução do calo ósseo em ambos os grupos, no mesmo momento de observação, não apresentou diferenças estatísticas, mesmo com concentrações plaquetárias diferentes no PRP. O modelo experimental, o tamanho do defeito ósseo e a localização, assim como o protocolo empregado, podem estar relacionados aos resultados do estudo.

Resultados benéficos são observados na Odontologia e em reconstruçõs maxilofaciais (MARX et al., 1998; MAZOR et al., 2004). O processo de reparo ósseo nos ossos do crânio e da mandíbula pode ser diferente dos ossos longos; além disso, os ossos da face são planos ou alongados (mandíbula) e as forças atuantes são diferentes das forças que atuam nos ossos longos, fatos que também poderão justificar os resultados controversos.

Estudos adicionais serão importantes para a padronização do protocolo de obtenção do plasma rico em plaquetas em cães, assim como a avaliação de seu efeito na regeneração óssea em procedimentos 
ortopédicos, associada aos diferentes enxertos e agentes osteoindutores.

\section{CONCLUSÃO}

A avaliação radiográfica simples e a densitometria óptica radiográfica não demonstraram aceleramento da formação do calo ósseo em fraturas de terço médio de rádio de cães tratados pela combinação do plasma rico em plaquetas e hidroxiapatita.

O presente estudo demonstrou que o plasma rico em plaquetas não altera o tempo de degradação da hidroxiapatita e que o substituto ósseo não promove efeitos adversos nos animais em estudo.

\section{FONTES DE AQUISIÇÃO}

${ }^{a}$ Gen-Phos ${ }^{\circledR}$ - Baumer S.A.- Mogi Mirim, SP, Brasil.

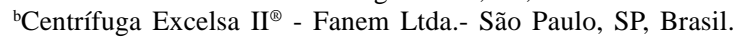
'Soluplastin ${ }^{\circledR}$ - Wiener Laboratórios S.A.I.C.- Rosario, Argentina. ${ }^{\mathrm{d}}$ Softium Sistemas de Informática Ltda-ME.

\section{COMITÊ DE ÉTICA}

O estudo foi aprovado pela Comissão de Bioética da Faculdade de Medicina Veterinária e Zootecnia da Universidade de São Paulo, estando de acordo com os princípios éticos de experimentação animal (protocolo no345/2003).

\section{AGRADECIMENTOS}

À Fundação de Amparo à Pesquisa do Estado de São Paulo (FAPESP), pelo apoio financeiro ao projeto. Ao Conselho Nacional de Desenvolvimento Científico e Tecnológico (CNPq), pela concessão de bolsa de mestrado a Silmara Bonomi da Silva. À Merial, pela doação de Front Line plus ${ }^{\circledR}$ e de vacinas Recombitek ${ }^{\circledR}$, e à Labyes, pela doação de Aziplus ${ }^{\circledR}$.

\section{REFERÊNCIAS}

AGHALOO, T.L. et al. Investigation of platelet-rich plasma in rabbit cranial defects: a pilot study. Journal of Oral and Maxillofacial Surgery, v.60, n.10, p.1176-1181, 2002.

ANITUA, E. Plasma rich in growth factors: preliminary results of use in the preparation of future sites for implants. International Journal of Oral \& Maxillofacial Implants, v.14, n.4, p.529-535, 1999.

BLOKHUIS, T.J. et al. Properties of calcium phosphate ceramics in relation to their in vivobehavior. Journal of Trauma, v.48, n.1, p.179-186, 2000.

CARLSON, E.R. Bone grafting the jaws in the 21st century: The use of platelet-rich plasma and bone morphogenetic protein. Alpha Omegan, v.93, n.3, p.26-30, 2000.

CONG, Z. et al. Reparing segmental bone defects with living porous ceramic cylinders: an experimental study in dog femora. Journal of Biomedical Materials Research, v.55, n.1, p.2832, 2001.
DALLARI, D. et al. In vivo study on the healing of bone defects treated with bone marrow stromal cells, platelet-rich plasma and freeze-dried bone allografts, alone and in combination. Journal of Orthopaedics Research, v.24, n.11, p.877-888, 2006.

FENNIS, J.P.M. et al. Mandibular reconstrution: a clinical and radiographic animal study on the use of autogenous scaffolds and platelet-rich plasma. International Journal of Oral \& Maxillofacial Surgery, v.31, n.3, p.281-286, 2002.

FENNIS, J.P.M. et al. Mandibular reconstrition: a histological and histomorphometric study on the use of autogenous scaffolds, particulate cortico-cancellous bone grafts and platelet rich plasma in goat. International Journal of Oral \& Maxillofacial Surgery, v.33, n.1, p.48-55, 2004.

FLORYAN, K.M.; BERGHOFF, W.J. Intraoperative use of autologous platelet-rich and platelet-poor plasma for orthopedic surgery patients. AORN Journal, v.80, n.4, p.668-678, 2004.

FONTANA, S. et al. Effect of platelet-rich plasma on the periimplant bone response: an experimental study. Implant Dentistry, v.13, n.1, p.73-78, 2004.

GERARD, D. et al. Effects of platelet-rich plasma on the healing of autologous bone grafted mandibular defects in dog. Journal of Oral and Maxillofacial Surgery, v.64, n.3, p.443-451, 2006.

GRAGEDA, E. et al. Bone formation in the maxillary sinus by using platelet-rich plasma: an experimental study in sheep. Journal of Oral Implantology, v.31, n.1, p.2-17, 2005.

HAUSCHILD, G. et al. Bioartificial bone grafting: tarsal joint fusion in a dog using a bioartificial composite bone graft consisting of ß-tricalciumphosphate and platelet rich plasma a case report. Veterinary and Comparative Orthopaedics and Traumatology, v.18, n.1, p.52-54, 2005.

JASKE, N. et al. Influence of PRP on autogenous sinus grafts. An experimental study on sheep. Clinical Oral Implants Research, v.14, n.5, p.578-583, 2003.

KIM, S.G. et al. Use of particulate dentin-plaster of Paris combination with/without platelet-rich plasma in the treatment of bone defects around implants. International Journal of Oral \& Maxillofacial Implants, v.17, n.1, p.86-94, 2002a.

KIM, S.G. et al. A comparative study of osseointegration of Avana implants in a demineralized freeze-dried bone alone or with platelet-rich plasma. Journal of Oral and Maxillofacial Surgery, v.60, n.9, p.1018-1025, 2002b.

LOUZADA, M.J.Q. et al. Metodologia para avaliação de densidade em imagem radiográfica. RBE- Caderno de Engenharia Biomédica, v.14, n.2, p.37-47, 1998.

MARX, R.E. et al. Platelet-rich plasm: growth factor enhancement for bone grafts. Oral Surgery Oral Medicine Oral Pathology Oral Radiology and Endodontics, v.85, n.6, p.638-646, 1998. 
MAZOR, Z. et al. Platelet-rich plasma for bone graft enhancement in sinus floor augmentation with simutaneous implant placement: patient series study. Implant Dentistry, v.13, n.1, p.65-72, 2004

OBARRIO, J.J. et al. The use of autologous growth factors in periodontal surgical therapy: platelet gel biotechnology - case reports. International Journal of Periodontics \& Restorative Dentistry, v.20, n.5, p.487-497, 2000.

PIERMATTEI, D.L.; FLO, G.L. Manual de ortopedia e tratamento das fraturas dos pequenos animais. São Paulo: Manole, 1999. 694p.

REMEDIOS, A. Bone and bone healing. Veterinary Clinics of North America: Small Animal Practice, v.29, n.5, p.1029-1042, 1999.

ROLDÁN, J.C. et al. Bone formation in the presence of plateletrich plasma vs. bone morphogenetic protein-7. Bone, v.34, n.1, p.80-90, 2004.

SÁNCHEZ, A.R. et al. Influence of platelet-rich plasma added to xenogenic bone grafts on bone mineral density associated with dental implants. International Journal of Oral \& Maxillofacial Implants, v.20, n.4, p.526-532, 2005.
SARKARA, M.R. et al. Bone formation in a long bone defect model using a platelet-rich plasma-loaded collagen scaffold. Biomaterials, v.27, n.9, p.1817-1823, 2006.

SIMON, E.N.M. et al. Reconstruction of the mandible after ablative surgery for the treatment of aggressive, benign odontogenic tumors in Tanzania: a preliminary study. International Journal of Oral \& Maxillofacial Surgery, v.35, n.5, p.421-426, 2006.

WEIBRICH, G. et al. Growth factor levels in the platelet-rich plasma produced by 2 different methods: Curasan-type PRP kit versus PCCS PRP system. International Journal of Oral \& Maxillofacial Implants, v.17, n.2, p.184-190, 2002.

WHITMAN, D.H. et al. Platelet gel: an autologous alternative to fibrin glue with applications in oral and maxillofacial surgery. Journal of Oral and Maxillofacial Surgery, v.55, n.11, p.1294-1299, 1997.

WILTFANG, J. et al. Effects of platelet-rich plasma on bone healing in combination with autogenous bone and bone substitutes in critical-size defects. An animal experiment. Clinical Oral Implants Research, v.15, n.2, p.187-193, 2004.

WILTFANG, J. et al. Sinus floor augmentation with $ß$ tricalciumphosphate (ß-TCP): does platelet-rich plasma promote its osseous integration and degradation? Clinical Oral Implants Research, v.14, n.2, p.213-218, 2003. 